\title{
WARMING LIGNOCAINE REDUCES THE PAIN OF INJECTION DURING LOCAL ANAESTHETIC EYELID SURGERY
}

\author{
R. W. D. BELL ${ }^{1}$, Z. A. BUTT ${ }^{1}$ and R. F. M. GARDNER ${ }^{2}$ \\ Edinburgh and Livingston
}

\begin{abstract}
SUMMARY
The injection of local anaesthetic solutions is frequently a painful and unpleasant experience for patients. $A$ double-masked randomised controlled trial was performed to study the potential benefit of warming lignocaine during local anaesthetic minor surgical procedures on the eyelids. The pain of subcutaneous injection of $1.5 \mathrm{ml}$ of $2 \%$ lignocaine at room temperature (cold) and body temperature (warm) was compared in 60 patients during the surgical incision of solitary meibomian cysts of one eyelid. Patients were randomly allocated to receive either warm or cold lignocaine. Pain was assessed subjectively by the use of a linear analogue pain scale ranging from 0 to 100 . The median pain score for the group receiving cold anaesthetic (19.5) was found to be greater than that for the warm group $(10.0 ; p=0.02)$. In conclusion, the simple process of warming lignocaine to $37^{\circ} \mathrm{C}$ was found to reduce the pain associated with its injection significantly. It is recommended that this technique be more widely adopted in order to minimise patients' discomfort.
\end{abstract}

Many oculoplastic procedures and the excision of small eyelid lesions are optimally performed under local anaesthetic. Infiltration of the skin and subcutaneous tissues with local anaesthetic solutions produces pain and a burning discomfort ${ }^{1.2}$ which is often severe enough to be the most unpleasant part of a minor surgical procedure. The need to relieve patient anxiety and minimise pain is important. There have been several reports suggesting that warming anaesthetic solutions reduces the pain associated with anaesthetic injection. ${ }^{3-5}$ There is, however, considerable disagreement in the literature

From: ${ }^{1}$ Princess Alexandra Eye Pavilion, Royal Infirmary of Edinburgh, Edinburgh, UK; ${ }^{2}$ St John's Hospital, Livingston, West Lothian, UK.

Correspondence to: Dr R. W. D. Bell, FRCOphth, Princess Alexandra Eye Pavilion, Royal Infirmary of Edinburgh, Chalmers Street, Edinburgh EH3 9HA, UK. Fax: (+44) 131-536-3897. as to the efficacy of this technique and much of the evidence is anecdotal. We have therefore designed our own double-masked randomised trial to assess the possible benefits of warming $2 \%$ plain lignocaine to body temperature before injection.

\section{PATIENTS, MATERIALS AND METHODS}

Sixty patients with solitary meibomian cysts of either the upper or lower eyelids underwent incision and curettage under local anaesthetic. Informed consent was obtained and they were randomly allocated to receive 2\% lignocaine hydrochloride (Pharma Hameln, Germany) at either room temperature $\left(17-20^{\circ} \mathrm{C}\right.$, 'cold') or body temperature $\left(37^{\circ} \mathrm{C}\right.$, 'warm'). There were 14 males and 16 females in the cold group, with an age range of 16-66 years and a mean of 40.8 years (SD 13.9). In the warm group there were 17 males and 13 females, with an age range of 24-83 years and a mean age of 48.7 years (SD 12.6).

A pilot study had shown that prewarming $2 \mathrm{ml}$ ampoules of lignocaine to $43^{\circ} \mathrm{C}$ in a thermostatically controlled water bath (Grant Instruments Cambridge) and then drawing up $1.5 \mathrm{ml}$ into a $2 \mathrm{ml}$ syringe resulted in a final temperature of $37{ }^{\circ} \mathrm{C}$ if the injection was given within 20-30 seconds. Room temperature vials were taken from the stock cupboard.

The study was performed in double-masked fashion. The patients were unaware of the solution temperature, and the injections were all given by a single investigator (R.F.M.G.) who had knowledge of the solution temperatures; however, a separate investigator who was masked to the trial asked the questions relating to the pain perceived. In all cases $1.5 \mathrm{ml}$ of $2 \%$ lignocaine in a $2 \mathrm{ml}$ syringe with a 25 gauge $16 \mathrm{~mm}$ needle.(Becton Dickinson) was used to infiltrate the subcutaneous tissues surrounding the lesion via a single entry site over a 4-5 second period, and patients were asked to comment on the pain of 
the injection rather than the needle entry. The subjective response to pain was assessed using a $100 \mathrm{~mm}$ linear visual analogue scale ranging from no pain at one end to the worst imaginable at the other. Linear analogue scores were measured to the nearest millimetre.

The pain scores from the two groups (warm and cold) were evaluated using the non-parametric Mann-Whitney $U$-test. In addition, further comparison was undertaken to determine whether there was a difference between warm and cold lignocaine when analysing pain scores obtained from injections in the upper and lower eyelids separately.

\section{RESULTS}

The results for the pain scores are summarised in Table I. The warm scores are lower than the cold in all three groups (all cases, upper lids, lower lids). The difference reaches statistical significance $(p=0.02)$ in the all cases group and borderline significance $(p=$ 0.06 ) in the upper lid group.

\section{DISCUSSION}

The technique of warming lignocaine to $37^{\circ} \mathrm{C}$ before injection has been adopted by dental practitioners; however, it has not received widespread acceptance by the medical profession. Boggia ${ }^{6}$ was the first to describe the practice of warming local anaesthetic agents in 1967, and since then there have been many anecdotal reports.

A review of the literature reveals several conflicting conclusions. Several studies have shown that warming lignocaine significantly reduced the pain of injection, ${ }^{3-5}$ whereas other workers have reported no difference. ${ }^{7,8}$ Only two studies were performed in double-masked fashion, ${ }^{3,8}$ and in two studies there was no standardisation of the injection site. ${ }^{5,7}$ In one study, varying volumes of anaesthetic solution were used, $^{7}$ while it has been shown that factors such as needle size, volume of anaesthetic and speed of injection may all affect the pain of injection. ${ }^{9}$

The reason for the decrease in pain associated with warm lignocaine is not known, although a number of

Table I. Summary of pain scores

\begin{tabular}{lcccc}
\hline & Number & $\begin{array}{c}\text { Median } \\
\text { scores }\end{array}$ & $\begin{array}{c}\text { Difference } \\
(\mathrm{CI})^{\mathrm{a}}\end{array}$ & $p$ value ${ }^{\mathrm{b}}$ \\
\hline $\begin{array}{l}\text { All cases } \\
\text { Cold }\end{array}$ & 30 & 19.5 & $9.0(1$ to 19$)$ & 0.02 \\
Warm & 30 & 10.0 & & \\
$\begin{array}{l}\text { Upper lid } \\
\text { Cold }\end{array}$ & 17 & 20.0 & $11.5(0$ to 29.5$)$ & 0.06 \\
Warm & 14 & 13.5 & & \\
$\begin{array}{l}\text { Lower lid } \\
\text { Cold }\end{array}$ & 13 & 17.5 & $6.0(-7$ to 20$)$ & 0.19 \\
Warm & 16 & 12.0 & & \\
\hline
\end{tabular}

aifference $=$ difference of population medians; CI $=95 \%$ confidence interval (binomial method).

${ }^{b}$ Calculated by the Mann-Whitney method. hypotheses have been suggested. Nerve endings are sensitive to cold, and greater pain may be due simply to greater nociceptor stimulation by the colder solution. Most local anaesthetics are weakly basic tertiary amines (represented here by $\mathrm{R} \equiv \mathrm{N}$ where $\mathrm{R}$ denotes organic radicals such as $-\mathrm{CH}_{3}$ ) that are commercially available as salts of strong acids (usually hydrochloric acid, $\mathrm{HCl}$ ) according to equation (1):

$$
\underset{\text { base }}{\mathrm{R} \equiv \mathrm{N}}+\mathrm{HCl} \longrightarrow \underset{\text { salt }}{\mathrm{R} \equiv \mathrm{NH}^{+} . \mathrm{Cl}^{-}}
$$

In aqueous solution, the salt ionises to yield the positively charged quaternary amine cation $\mathrm{R} \equiv \mathrm{NH}^{+}$which is in turn in dissociation equilibrium with the base, as follows:

$$
\begin{gathered}
\mathrm{R} \equiv \mathrm{NH}^{+} \rightleftharpoons \\
\text { cation }
\end{gathered} \underset{\text { base }}{\mathrm{R} \equiv \mathrm{N}}+\mathrm{H}^{+}
$$

From the Mass Law the direction of the dissociation will vary with the hydrogen ion concentration $(\mathrm{pH})$ of the solution. When the hydrogen ion concentration is low (i.e. in alkaline surroundings) the reaction proceeds to the right and most of the local anaesthetic is in the base form; likewise a high hydrogen ion concentration favours the cationic species. Under equilibrium conditions the dissociation constant $\left(K_{\mathrm{a}}\right)$ of the reaction is defined by:

$$
K_{\mathrm{a}}=\frac{\left[\mathrm{H}^{+}\right][\text {base }]}{\text { [cation] }}
$$

where the square brackets denote concentration. It has been postulated that aromatic amine local anaesthetics penetrate cell membranes in the uncharged form and bind to the putative intracellular receptor(s) in the charged form. ${ }^{10}$ The ratio of these two species is determined by the dissociation constant of the anaesthetic and the $\mathrm{pH}$ of the medium. The $K_{\mathrm{a}}$ of a given anaesthetic is an equilibrium quantity and it has been shown that the $K_{\mathrm{a}}$ increases with increases in temperature. ${ }^{11}$ This implies that the higher temperature favours the uncharged species, facilitating more rapid intracellular diffusion and a faster onset of neuronal blockade. ${ }^{11}$ A similar theory has been proposed for the reduction in the pain of injection after the alkalinisation of local anaesthetic solutions. ${ }^{12}$ This has been achieved by the addition of bicarbonate, ${ }^{13}$ however, this would involve the inconvenience of mixing two solutions, which could result in a reduction in solubility and stability of the anaesthetic agent. $^{14}$

In conclusion, local anaesthesia is the method of choice during minor operations involving the eyelids such as incision of chalazions, excision of lid tumours and entropion and ectropion repairs. Indeed, even relatively major oculoplastic procedures, such as 
ptosis correction, lend themselves particularly well to local anaesthesia, allowing the lid height to be adjusted on the operating table. These cases are very common and constitute a significant proportion of an ophthalmologist's workload. Often the patient's main fear is of the anaesthetic injection, and we have shown that these unpleasant procedures can be made more acceptable by the relatively simple process of warming the anaesthetic solution prior to injection. A thermostatically controlled waterbath can be conveniently used for this purpose and set up prior to the beginning of an operating list. Dry incubators, baby bottle warmers and yoghurt makers are also available and used by dentists and anaesthetists, although these have the drawback of needing to be thermometer verified.

We would like to thank Mr Bill Adams of the Medical Statistics Department, University of Edinburgh, for his kind help with the statistical analysis.

The authors state that they have no commercial interest in the equipment described herein.

Key words: Local anaesthesia, Warming lignocaine, Pain, Meibomian cysts.

\section{REFERENCES}

1. Morris RW, Whish DKM. A controlled trial of pain on skin infiltration with local anaesthetics. Anaesth Intensive Care 1984;12:113-4.

2. Morris R, McKay W, Mushlin P. Comparison of pain associated with intradermal and subcutaneous infiltration with various local anaesthetic solutions. Anaesth Analg 1987;66:1180-2.
3. Davidson JAH, Bloom SJ. Warming lignocaine to reduce pain associated with injection. BMJ 1992;305: 617-8.

4. Cragg AH, Berbaum K, Smith TP. A prospective blinded trial of warm and cold lidocaine for intradermal injection. AJR 1988;150:1183-4.

5. Bainbridge LC. Comparison of room temperature and body temperature local anaesthetic solutions. Br J Plast Surg 1991;44:147-8.

6. Boggia R. Heating local anaesthetic cartridges. $\mathrm{Br}$ Dent J 1967;122:287.

7. Dalton AM, Sharma A, Redwood M, Wadsworth J, Touquet R. Does the warming of local anaesthetic reduce the pain of its injection? Arch Emerg Med 1989;6:247-50.

8. Kaplan PA, Lieberman RP, Vonk BM. Does heating lidocaine decrease the pain of injection? AJR 1987; 148:1291.

9. Gormley DE. Local anaesthesia: pain control with proper injection technique. J Dermatol Surg Oncol 1987;1:13, 35-6.

10. Ritchie JM, Greengard P. On the active structure of local anaesthetics. J Pharmacol Exp Ther 1961;133: 241-5.

11. Kamaya H, Hayes JJ, Ueda I. Dissociation constants of local anaesthetics and their temperature dependence. Anaesth Analg 1983;62:1025-30.

12. Christoph RA, Buchanan L, Begalla K, Schwartz S. Pain reduction in local anaesthetic administration through pH buffering. Ann Emerg Med 1988;17: 117-20.

13. Martin AJ. pH adjustment and discomfort caused by the intradermal injection of lignocaine. Anaesthesia 1990;45:975-8.

14. Bonhomme L, Benhamou D, Martre H, Preaux N. Chemical stability of bupivacaine and epinephrine in pH adjusted solutions. Anaesthesiology 1987;67:A279. 